\title{
Resveratrol and acetyl-resveratrol modulate activity of VEGF and IL-8 in ovarian cancer cell aggregates via attenuation of the NF-kB protein
}

\author{
Alexandria B. Tino ${ }^{1}$, Kenny Chitcholtan ${ }^{2^{*}}$ D, Peter H. Sykes ${ }^{1}$ and Ashley Garrill ${ }^{3}$
}

\begin{abstract}
Background: Key features of advanced ovarian cancer include metastasis via cell clusters in the abdominal cavity and increased chemoresistance. Resveratrol and derivatives of resveratrol have been shown to have antitumour properties. The purpose of this study was to investigate the effect of resveratrol and acetyl-resveratrol on 3D cell aggregates of ovarian cancer, and establish if NF-kB signalling may be a potential target.

Methods: Poly-HEMA coated wells were used to produce 3D aggregates of two ovarian cancer cell lines, SKOV-3 and OVCAR-5. The aggregates were exposed to 10,20 or $30 \mu \mathrm{M}$ resveratrol or acetyl-resveratrol for 2, 4 or 6 days. Cell growth and metabolism were measured then ELISA, western blot and immunofluorescence were utilised to evaluate VEGF, IL-8 and NF-KB levels.

Results: Resveratrol and acetyl-resveratrol reduced cell growth and metabolism of SKOV-3 aggregates in a doseand time-dependent manner. After 6 days all three doses of both compounds inhibited cell growth. This growth inhibition correlated with the attenuated secretion of VEGF and a decrease of NF-KB protein levels. Conversely, the secretion of IL-8 increased with treatment. The effects of the compounds were limited in OVCAR-5 cell clusters.

Conclusions: The results suggest that resveratrol and its derivative acetyl-resveratrol may inhibit in vitro 3D cell growth of certain subtypes of ovarian cancer, and growth restriction may be associated with the secretion of VEGF under the control of the NF-KB protein.
\end{abstract}

Keywords: Ovarian cancer, Resveratrol, Acetyl-resveratrol, VEGF, NF-KB, Cell clusters, IL-8

\section{Background}

Ovarian cancer is a lethal gynaecological cancer and is the seventh most common cause of cancer death among women [1]. The majority of women present with an advanced stage of the disease [2]. The current treatment options of debulking surgery and chemotherapy are generally not curative in advanced stages of the disease due to recurrence and chemoresistance [3]. Therefore, alternative treatments that target cancer cells, reduce tumour growth and increase tumour-free survival are of great importance.

\footnotetext{
* Correspondence: kenny.chitcholtan@otago.ac.nz

2Obstetrics and Gynaecology Department Christchurch Women's Hospital,

Private Bag 4711, Christchurch 8140, New Zealand

Full list of author information is available at the end of the article
}

Ovarian cancer metastasises via the fluid in the peritoneal cavity. Cells slough off the primary tumour and form small 3D clusters or aggregates in the peritoneal fluid. The accumulation of peritoneal fluid, which is known as ascites, is often associated with advanced ovarian cancer and correlates with poor prognosis [4]. The microenvironment of the ascitic fluid is rich in a wide range of growth factors and cytokines, and these are believed to sustain cell cluster survival, growth and secondary site establishment [5]. Relatively little is known, however, about the interactions between ascitic fluid components and the 3D aggregates. The 3D aggregates of ovarian cancer cells are integral to metastasis, and are possibly involved with the development of chemoresistance [6]. Few studies have investigated the use of 
potential therapeutic agents against the 3D aggregates of ovarian cancer.

Our knowledge of ovarian cancer aggregate survival in ascitic fluid is limited. However, studies on other types of solid tumour, coupled with analyses of pertinent proteins suggest that angiogenic and inflammatory mediators may play a significant role. Of the numerous proangiogenic cytokines vascular endothelial growth factor (VEGF) is one of the most well described. In addition to being a key regulator of angiogenesis, it also enhances cell survival, proliferation and migration [7, 8]. Studies have revealed that VEGF is over expressed by ovarian cancer $[9,10]$. Interleukin-8 (IL-8) is another regulation protein involved in tumorigenic activities in cancers, and has been reported to be over expressed in ovarian cancer [11-13], suggesting its importance to ovarian cancer carcinogenesis.

There is evidence that VEGF and IL-8 expression in ovarian cancer are under the transcriptional control of nuclear factor kappaB (NF-kB) [14]. The NF-kB family of transcription factors are activated via two signalling pathways [15]. In normal cells, NF- $\mathrm{kB}$ activation is very tightly regulated, but constitutive activation has been identified in a range of cancers [16-18] suggesting that NF- $\mathrm{KB}$ signalling may be important in cancer survival. Furthermore, in some cancer types the activation of NF$\mathrm{KB}$ correlates with the expression of VEGF [19] and IL8 [20]. However, this correlation is not well understood in ovarian cancer.

The polyphenol resveratrol is a possible inhibitor of the NF- $\mathrm{KB}$ signalling pathway in ovarian cancer. Resveratrol is one of the major antioxidants found in the skin of red grapes and has anti-inflammatory [21], cardioprotective [22] and anti-carcinogenic properties [23]. It has been linked to the inhibition of NF- $\mathrm{KB}$ in prostate [24] and lung cancer [25], and the down regulation of VEGF [26] and IL-8 [27]. However, there have been no reports on the effects of resveratrol on NF- $k B$ activity, cytokine expression or their correlation with the growth of ovarian cancer clusters.

Although resveratrol appears to be a very promising cancer treatment, it has low bioavailability [28, 29], because of this the resveratrol derivative acetyl-resveratrol has aroused interest. In chemopreventive and chemotherapeutic studies, it appears to possess the same characteristics as resveratrol, but may not undergo such rapid metabolism in the liver and with increased cellular uptake may have greater bioavailability [30]. The hydroxyl groups of resveratrol are acetylated in acetylresveratrol which accounts for it being a more stable compound and increased uptake in the body [31].

In the present study, we examined the effect of resveratrol and acetyl-resveratrol on cell growth and on the production of regulatory factors in $3 \mathrm{D}$ aggregates of two ovarian cancer cell lines. Our data shows that both compounds significantly inhibit cell growth, VEGF secretion and NF- $\kappa B$ activation in a time-, dose- and cell line dependent manner. The secretion of IL-8 increased.

\section{Methods \\ Cell culture}

The human ovarian adenocarcinoma cell lines SKOV-3 and OVCAR-5 were obtained from Dr. Judith McKenzie, Haematology Research group, University of Otago, Christchurch, New Zealand. Both cell lines were maintained in Dulbecco's Modified Eagle Medium $\left(\mathrm{GIBCO}^{\circ}\right.$, Life Technologies, New Zealand), supplemented with $10 \%$ fetal bovine serum (GIBCO ${ }^{\circ}$, Life Technologies, New Zealand), PenStrep (GIBCO ${ }^{\circ}$, Life Technologies, New Zealand) at a working concentration of 100 units/ $\mathrm{ml}$ penicillin and $100 \mu \mathrm{g} / \mathrm{ml}$ streptomycin, $2 \mathrm{mM}$ Gluta$\operatorname{MAX}^{\text {su }}\left(\mathrm{GIBCO}^{\circ}\right.$, Life Technologies, New Zealand) and 2 $\mu \mathrm{g} / \mathrm{ml}$ Fungizone $^{\circ}$ (Life Technologies, New Zealand). The supplemented media is henceforth referred to as working media. SKOV-3 and OVCAR-5 cells in working media were continuously maintained in a culture flask at $37{ }^{\circ} \mathrm{C}$ in a humidified $5 \% \mathrm{CO}_{2}$ atmosphere incubator.

\section{Production of 3D aggregates}

To prevent adhesion of cells to culture plates, 12-well culture plates were pre-coated with $24 \mathrm{mg} / \mathrm{ml}$ Polyhydroxyethylmethacrylate (poly-HEMA) (Sigma, New Zealand) prior to cell culturing $(0.5 \mathrm{ml} /$ well). Prior to coating, poly-HEMA was fully dissolved in $95 \%$ ethanol at a concentration of $24 \mathrm{mg} / \mathrm{ml}$ and was heated to approximately $70{ }^{\circ} \mathrm{C}$. After the poly-HEMA was placed in the wells the plates were left overnight at $37{ }^{\circ} \mathrm{C}$ on an orbital shaker. Prior to cell culture, the coated wells were washed once with PBS at $\mathrm{pH}$ 7.4. To detach the cell monolayer of the SKOV-3 and OVCAR-5 cell lines from the flask surface, they were incubated with $1 \mathrm{x}$ trypsinEDTA for 20-30 min. Cells were counted with a haemocytometer to determine the concentration of the cells in suspension. Cells were then plated at a density of 200,000 cells/well and were incubated at $37{ }^{\circ} \mathrm{C}$ in a humidified $5 \% \mathrm{CO}_{2}$ atmosphere for 6 days. Over this time the cells became clusters and aggregates. Working media was refreshed every 2 days with $1 \mathrm{ml}$ of fresh working media.

\section{Treatment with resveratrol, acetyl-resveratrol and Bay 11-7085}

Resveratrol and acetyl-resveratrol were provided by Dr. Saurabh Shah, Biotivia (USA). A NF-kB inhibitor, Bay 11-7085, was purchased Sigma-Aldrich (Auckland, New Zealand). Resveratrol was dissolved in a 50:50 combination of PBS and DMSO, acetyl-resveratrol and Bay 11-7085 were dissolved in 100\% DMSO. 
Fresh working media containing the relevant compounds (at concentrations of 10, 20 and $30 \mu \mathrm{M}$ ) was replaced every 2 days for up to 6 days. Thus, at the endpoint of culturing the cells had a total incubation time of 8,10 or 12 days respectively; 6 days developing the aggregates and 2, 4 or 6 days of treatment. For all experiments, the final concentration of DMSO used in controls was the concentration of DMSO that was present in the $30 \mu \mathrm{M}$ treatments. At least 4 independent experiments were carried out for each treatment and within each experiment there were 3 replicates.

\section{Growth determination using the crystal violet assay}

Growth of the 3D aggregates was quantified indirectly using crystal violet staining. In brief, cell aggregates were isolated and incubated with 1x trypsin-EDTA for $20 \mathrm{~min}$ at $37{ }^{\circ} \mathrm{C}$. Cells were washed twice with PBS (pH 7.4) and were incubated for a further $15 \mathrm{~min}$ at $37{ }^{\circ} \mathrm{C}$ with $2 \mathrm{mg} / \mathrm{ml}$ crystal violet in $2 \%(\mathrm{v} / \mathrm{v})$ ethanol in milliQ water. The cells were then washed with milliQ water to remove unbound crystal violet, and were isolated by centrifugation at $1500 \mathrm{rpm}$ for $5 \mathrm{~min}$. The supernatant was removed and the process repeated 3 times until the supernatant was colourless. Cells were then lysed in $10 \%(\mathrm{w} / \mathrm{v})$ sodium dodecyl sulphate (SDS) solution. $200 \mu \mathrm{l}$ of the homogenous cell lysate was then loaded onto a 96-well plate. The optical density was determined at $560 \mathrm{~nm}\left(\mathrm{OD}_{560}\right)$ using a microplate reader (SpectraMax M5, Molecular Devices).

\section{Cellular metabolism determination using the Alamar blue assay}

On the $6^{\text {th }}$ day of treatment with compounds, $0.5 \mathrm{ml}$ media was removed from each well and $50 \mu \mathrm{l}$ of Alamar blue dye (ThermoFisher Scientific, New Zealand) added to cell aggregates. Aggregates were incubated at $37{ }^{\circ} \mathrm{C}$ with the dye for $4 \mathrm{~h}$ after which $200 \mu \mathrm{l}$ of media from each well was transferred to a 96-well plate. The absorbance at 570 and $600 \mathrm{~nm}$ was measured using a microplate reader (SpectraMax M5, Molecular Devices). Cellular metabolism was calculated from the difference of absorbance at 600 and $570 \mathrm{~nm}$.

\section{Detection of vascular endothelial growth factor (VEGF) and interleukin-8 (IL-8)}

The conditioned media of the control and treated cells (2, 4 or 6 days) was used to determine secreted VEGF and IL-8 levels. The conditioned media were centrifuged at $1500 \mathrm{rpm}$ to remove cell debris and stored at $-80{ }^{\circ} \mathrm{C}$ until assayed using the DuoSet Human VEGF ELISA kit (R\&D System, New Zealand) and the DuoSet Human IL-8 ELISA kit (R\&D System, New Zealand). The assays were carried out according to the manufacturer's instructions. Samples were diluted 50\%, the amount of VEGF or IL-8 was determined by comparing absorbance of each well to a standard curve and corrected for total protein.

\section{Western blotting}

Cell aggregates were harvested after their respective treatments by centrifugation at $1500 \mathrm{rpm}$ for $5 \mathrm{~min}$ and the cell pellet was resuspended in cold RIPA buffer containing protease inhibitor cocktail tablets (Complete Mini, Roche, New Zealand). The cell lysates were left on ice for $30 \mathrm{~min}$ to ensure total cell lysis. Total protein was determined using a Pierce ${ }^{\mathrm{TM}}$ BCA protein assay kit (ThermoFisher Scientific, New Zealand) according to the manufacturer's instructions. Sample buffer $(0.2 \%$ (v/ v) bromophenol blue, 25\% (v/v) glycerol, 10\% SDS in Tris- $\mathrm{HCl}$ and $\mathrm{pH}$ 6.8) was added and protein lysates were boiled for $10 \mathrm{~min}$. Samples $(10 \mu \mathrm{g}$ protein) were fractionated in 5-12\% SDS-PAGE gels and transferred to PDVF membranes (Bio-Rad Laboratories, Hercules, USA). The markers used were MagicMark Western Protein Standard (Thermofisher, New Zealand) and Precision Plus Protein Standard (Bio-Rad, Hercules, New Zealand). The membranes were blocked for $60 \mathrm{~min}$ with either 5\% (w/v) nonfat skim milk (Pams brand, New World, New Zealand) or $1 \%$ (w/v) bovine serum albumin (ThermoFisher Scientific, New Zealand) in 1\% tweenTBS. Antibodies were diluted to $1 / 500$ to $1 / 1000$ with the appropriate blocking solution, and membranes were incubated with primary antibodies overnight at $4{ }^{\circ} \mathrm{C}$. Membranes were developed using either donkey antimouse IgG-AP or goat anti-rabbit IgG-AP secondary antibodies (Santa Cruz, CA, USA, 1:10,000). Antibody localisation was determined using a chemiluminescent detection kit (Amersham ECL Prime Western Blotting Detection Reagent Kit, GE Healthcare) and the bands visualized using Alliance 4.7, Unitec (Cambridge, UK). The primary antibodies used were PCNA (sc-25280), $\mathrm{pI} \kappa \mathrm{B} \alpha(\mathrm{sc}-8404), \mathrm{NF}-\kappa \mathrm{B}$ (sc-372), pNF-kB (sc-33020) and GAPDH (sc-25778), all purchased from Santa Cruz Biotechnology Inc. (Santa Cruz, CA, USA).

\section{Immunofluorescence}

Cell aggregates were harvested after treatments, they were then centrifuged and the supernatant removed. 1 $\mathrm{ml}$ of ice cold mixture of methanol:acetone (50:50\% (vol/ vol)) solution was added to the OVCAR-5 and SKOV-3 cell aggregates and the samples were stored at $-20{ }^{\circ} \mathrm{C}$ until analysis. Prior to sectioning, SKOV-3 aggregates were stained with the aniline blue dye solution $(1 \%$ in water (Sigma-Aldrich LTD, New Zealand)) for $20 \mathrm{~min}$ and washed with PBS twice. The stained SKOV-3 aggregates were then imbedded in CryO-Z-T solution (Ted 
Pella Inc., USA) and frozen overnight at $-80{ }^{\circ} \mathrm{C}$. SKOV-3 samples were then sectioned into $7 \mu \mathrm{M}$ thick slices, two slices were placed on appropriately labelled Superfrost plus slides (Menzel-glaser, Germany), 6 slices per sample were collected, and stored at $-20{ }^{\circ} \mathrm{C}$ until analysis.

The OVCAR-5 cell clusters were removed from the methanol/acetone solution, washed with PBS pH 7.4 and placed onto slides. Slides of both cell lines were dried and blocking buffer added for $1 \mathrm{~h}$ at room temperature. Primary antibodies to detect NF- $\mathrm{kB}$ or pNF- $\mathrm{kB}$ proteins were diluted to $1: 200$ in $2 \%$ BSA in PBS, added to the slides and the slides were incubated overnight at $4{ }^{\circ} \mathrm{C}$. The secondary antibody goat anti-rabbit IgG conjugated with Atto $594 \mathrm{~nm}$ (Sigma-Aldrich LTD, New Zealand, 1:1000) was added to slides which were then incubated for $1 \mathrm{~h}$ at $37{ }^{\circ} \mathrm{C}$, and then samples were stained with $10 \mu \mathrm{g} / \mathrm{ml}$ Hoechst (Invitrogen, New Zealand) for 20 min. The slides were washed extensively with PBS + $0.1 \%$ Tween-20, $\mathrm{pH}$ 7.4. Cells were observed and imaged with an epifluorescence microscope (AxioVision 4.5. Apotome software, Carl Zeiss, Oberkochen, Germany).

\section{Statistical analysis}

At least four independent experiments were carried out for each treatment and these were statistically analyzed using GraphPad Prism software (La Jolla, CA, USA). $p<$ 0.05 was considered to indicate statistical significance determined by one way ANOVA. All data are presented as mean $\pm \mathrm{SEM}$.

\section{Results}

Attenuation of cellular growth and metabolism by resveratrol and acetyl-resveratrol

It has been previously shown that resveratrol reduces the growth of monolayer and clusters of ovarian cancer cell lines [32]. We further examined this in 3D cell aggregates using concentrations of resveratrol and acetyl-resveratrol that were closer to levels found in human serum [29], using the Alamar blue dye assay (Fig. 1). The metabolism of the SKOV-3 aggregates was significantly reduced by between 20 and $40 \%$ after 4 and 6 days exposure to resveratrol (Fig. 1a). In contrast, after 2, 4 and 6 days of treatment the OVCAR-5 clusters were unaffected (Fig. 1b). Likewise, acetyl-resveratrol did not have an effect on either cell line (Fig. 1c and d).

Next, we investigated the effect of the compounds on cell growth (Fig. 2) by using the crystal violet assay. SKOV-3 cell growth in 3D cell aggregates was significantly decreased after 2 and 4 days of treatment with $30 \mu \mathrm{M}$ resveratrol and after 6 days treatment at all three concentrations tested (Fig. 2a). It had no effect on growth of OVCAR-5 cell clusters (Fig. 2b). Similarly, acetyl-resveratrol significantly decreased the growth of SKOV-3 cells after 6 days treatment at each of the concentrations tested but had no effect on the OVCAR-5 cells (Fig. 2c and d). Both resveratrol and acetyl-resveratrol did not increase apoptotic cells in both cell lines (data not shown).
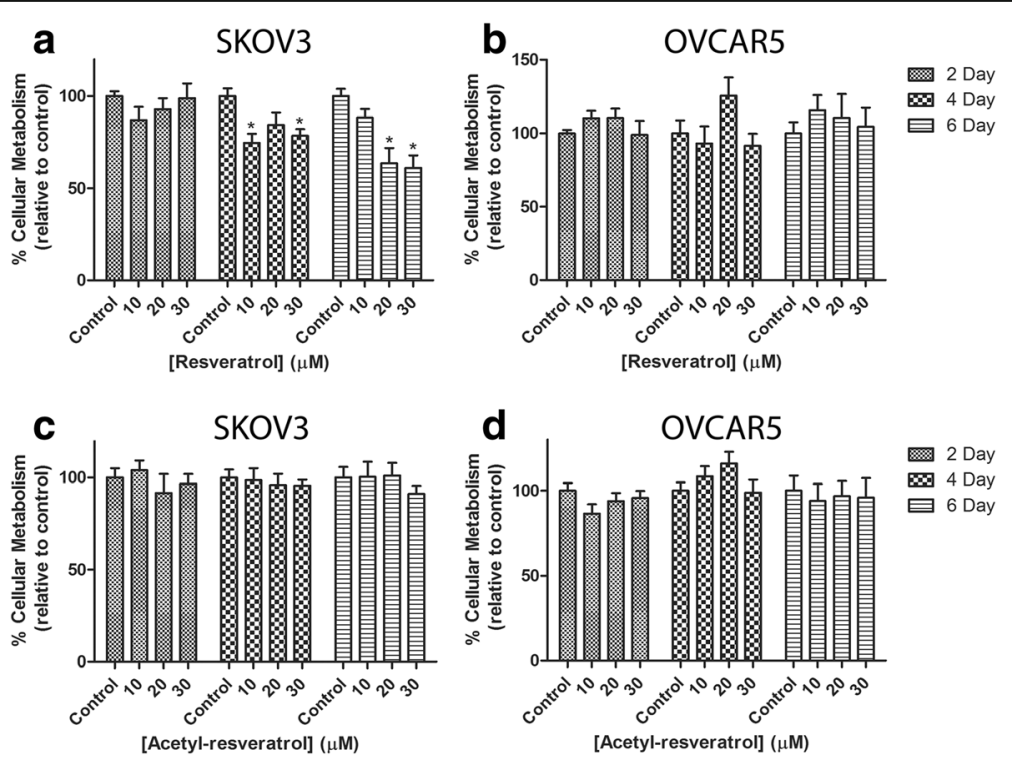

Fig. 1 Cellular metabolism relative to control of SKOV-3 aggregates after treatment with resveratrol (a) or acetyl-resveratrol (c) for 2, 4 or 6 days. Cellular metabolism relative to control of OVCAR-5 clusters after treatment with resveratrol (b) or acetyl-resveratrol (d) for 2, 4 or 6 days. * indicates statistical significance $p<0.05$ compared to the control. $n=4$ independent experiments in triplicate 

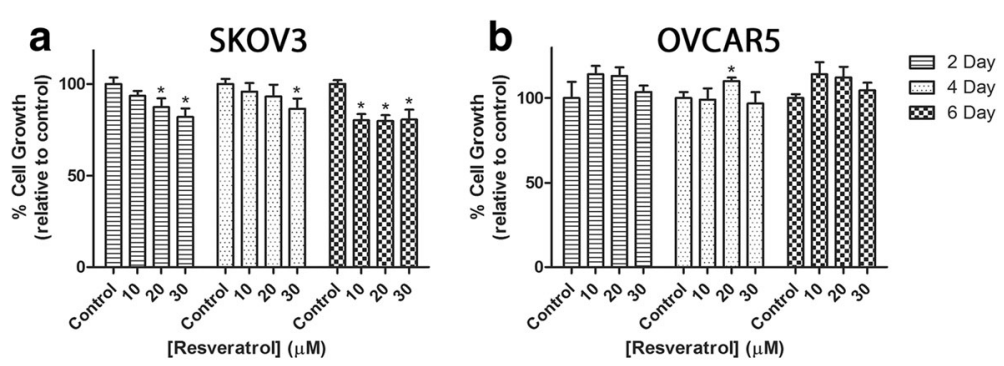

啰 4 Day

종 Day
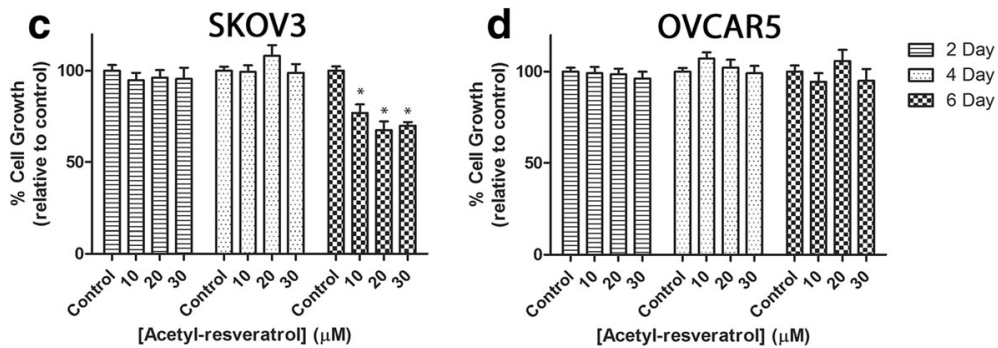

Fig. 2 Cell growth relative to control of SKOV-3 aggregates after treatment with resveratrol (a) or acetyl-resveratrol (c) for 2, 4 or 6 days. Cell growth relative to control of OVCAR-5 clusters after treatment with resveratrol (b) or acetyl-resveratrol (d) for 2, 4 or 6 days. * indicates statistical significance $p<0.05$ compared to the control. $n=4$ independent experiments in triplicate

\section{Attenuation of Vascular Endothelial Growth Factor (VEGF)} production by resveratrol and acetyl-resveratrol

VEGF is a glycoprotein that is a key regulator of angiogenesis. Angiogenesis is fundamental to the development of solid cancerous tumours as oxygen and nutrients are required for the cancer to flourish [33]. Elevated levels of VEGF have been observed in ascitic fluid and these correlate with a poor prognosis [34]. To assess the effect of the resveratrol and acetyl-resveratrol on the production of
VEGF we used an ELISA. Resveratrol at a concentration of $30 \mu \mathrm{M}$ reduced VEGF production in SKOV-3 cell aggregates by 41 and $54 \%$ after 4 and 6 days respectively (Fig. 3a). Similar results were observed with acetyl-resveratrol (reductions of 49 and $58 \%$ respectively). The basal secretion of VEGF by OVCAR-5 clusters was much lower than for SKOV-3 cells, between 0.4 and $1.1 \mathrm{ng} / \mathrm{ml} / \mathrm{mg}$ (Fig. $3 \mathrm{~b}$ and d) and the secretion levels were unchanged in the presence of both resveratrol (Fig. 3b) and acetyl-resveratrol (Fig. 3d).
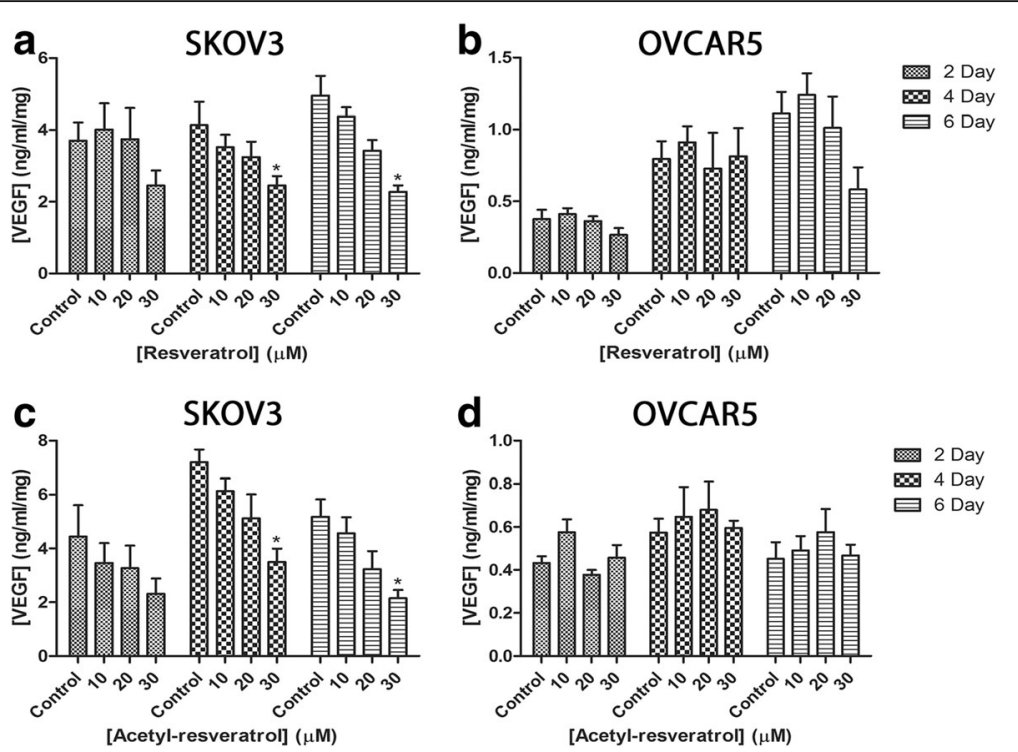

Fig. 3 The secretion of vascular endothelial growth factor (VEGF) of SKOV-3 aggregates after treatment with resveratrol (a) or acetyl-resveratrol (c) for 2, 4 or 6 days. The secretion of VEGF of OVCAR-5 clusters after treatment with resveratrol (b) or acetyl-resveratrol (d) for 2, 4 or 6 days. * indicates statistical significance $p<0.05$ compared to the control. $n=4$ independent experiments in triplicate 
Resveratrol and Acetyl-resveratrol increase the secretion of Interleukin-8 (IL-8)

The chemokine IL- 8 is induced by inflammatory stimuli and is responsible for activation of neutrophils under normal conditions [35]. There is evidence of IL-8 sustaining cancer cell survival [36] and it is over expressed in ovarian cancer $[13,37]$. We used an ELISA to gauge the effects of resveratrol and acetyl-resveratrol and found that the compounds caused an increase in the production of IL-8 in both cell lines (Fig. 4). Resveratrol more than doubled the level of IL-8 produced by SKOV3 's cell aggregates at all three concentrations after 4 and 6 days (Fig. 4a) and an increasing trend was also observed in OVCAR-5 clusters (Fig. 4b). Acetyl-resveratrol also had a profound effect on SKOV-3 IL-8 secretion (Fig. 4c) and again an increasing trend was observed in OVCAR-5 (Fig. 4d).

\section{Effects of resveratrol and acetyl-resveratrol on the expression and activation of NF-KB protein}

The signalling pathways that control cancer cell survival and proliferation are of great interest for targeted cancer cell therapy. There are many cascades involved in cancer cell growth, but a prominent one, the Nuclear Factor Kappa B (NF-kB) pathway, has also been linked to the secretion of VEGF and IL-8 in other cancers such as breast [19] and prostate cancer [20]. There is also evidence to suggest that resveratrol may attenuate NF- $\mathrm{kB}$ [24]. Therefore, we hypothesised that NF- $\mathrm{kB}$ signalling is a key signalling pathway in ovarian cancer and is a potential primary target of resveratrol. In order to investigate the effects of resveratrol and acetylresveratrol on NF- $\mathrm{kB}$ protein and its phosphorylation (pNF- $\mathrm{kB}$ ), we employed western blotting and immunofluorescence. We stained frozen sections of SKOV-3 aggregates and OVCAR-5 clusters for the heterodimer NF- $\kappa B$ and pNF- $\kappa B$. There was an obvious difference in the abundance of NF- $k B$ and pNF- $k B$ between the two cell lines, with SKOV-3 expressing a greater amount of the proteins (Fig. 5). The NF- $\mathrm{kB}$ molecule was observed inside the nucleus (red dots) and cytoplasm of SKOV-3 cells (Fig. 5a). The immunostaining of pNF-kB control cells was also located inside the nucleus and cytoplasm with a diffused staining pattern (Fig. 5b). After treatment with resveratrol (Fig. 5c and d) and acetyl-resveratrol (Fig. 5e and f) the abundance of both proteins at the nucleus was reduced. There was a low abundance of NF- $\kappa B$ and pNF- $\mathrm{BB}$ in OVCAR-5 cell clusters (Fig. $5 \mathrm{~g}$ and $h$ ).

To support the immunofluorescent imaging, we then examined the expression and activation of NF- $\mathrm{kB}$ after 6 days of treatment with the compounds using western blots. We also investigated two additional proteins that

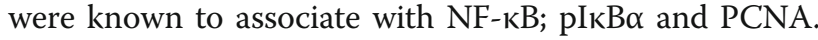
As shown in Fig. 6, SKOV-3 cell lysates pNF-kB (Fig. 6a and $\mathrm{c}$ ) and NF-KB (Fig. 6a and d) showed high expression which were significantly reduced by resveratrol. In OVCAR-5 cell lysates, NF- $\mathrm{kB}$ expression was much weaker and unaffected by resveratrol (Fig. $6 \mathrm{~b}$ and g).and pNF- $\kappa B$ was not detected (Fig. 6b). pІкB $\alpha$ expression (Fig. $6 \mathrm{~b}$ and $\mathrm{h}$ ) was in contrast much stronger but was also unaffected by resveratrol. Acetyl-resveratrol at 20
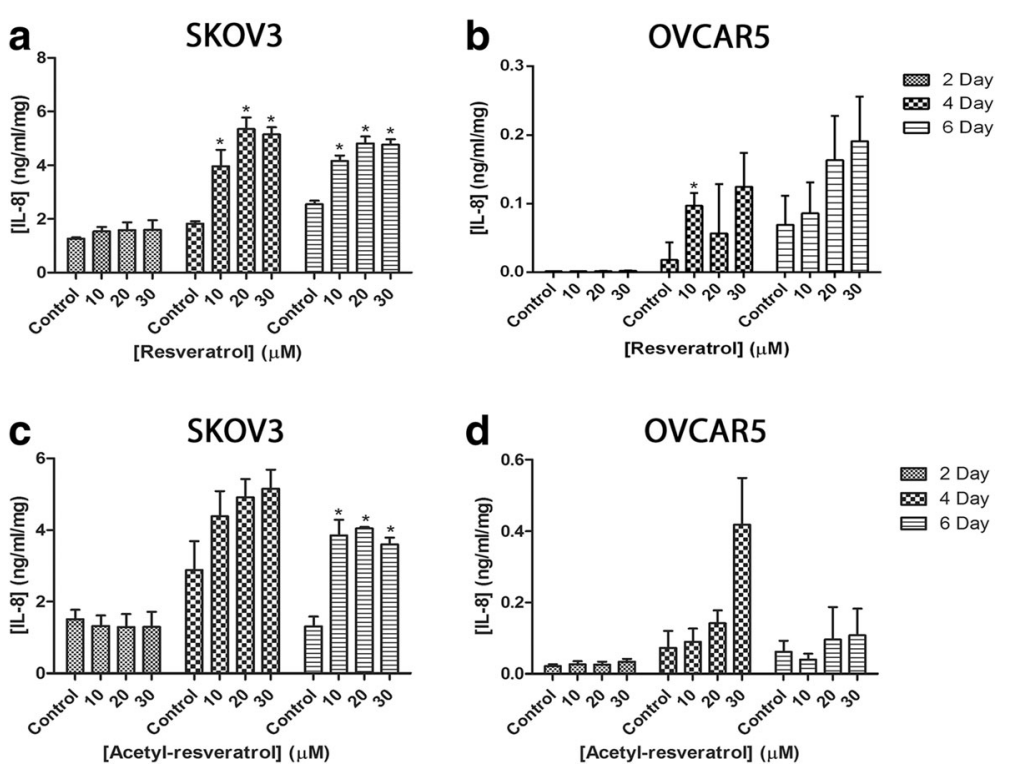

Fig. 4 The secretion of interleukin-8 (IL-8) of SKOV-3 aggregates after treatment with resveratrol (a) or acetyl-resveratrol (c) for 2, 4 or 6 days. The secretion of IL-8 of OVCAR- 5 clusters after treatment with resveratrol (b) or acetyl-resveratrol (d) for 2, 4 or 6 days. * indicates statistical significance $p<0.05$ compared to the control. $n=4$ independent experiments in triplicate 


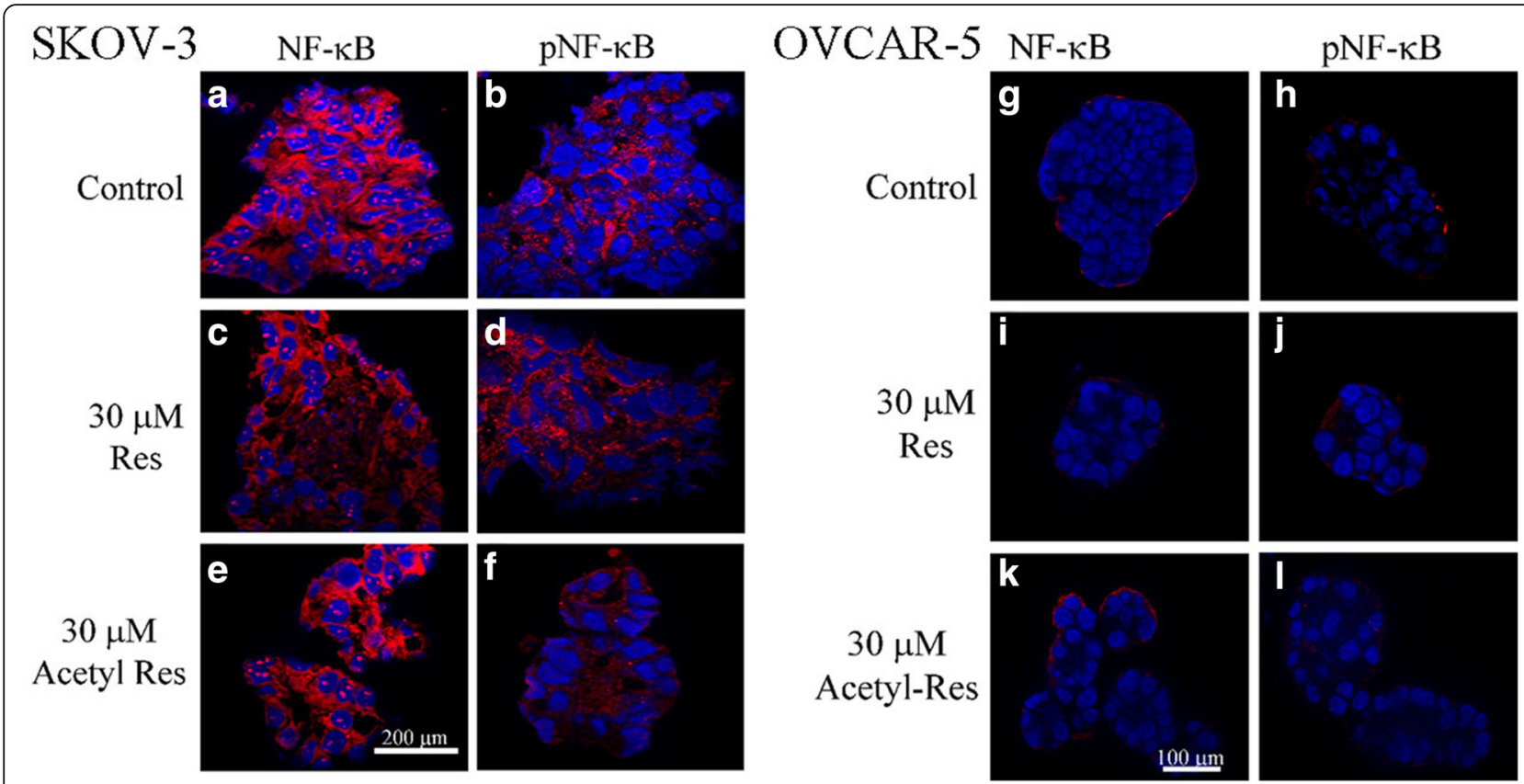

Fig. 5 Immunofluorescent images of NF-kB and pNF-KB in frozen cut sections of SKOV-3 control aggregates (a and $\mathbf{b}$ ) treated with resveratrol (c and $\mathbf{d}$ ) or acetyl-resveratrol (e and $\mathbf{f}$ ) for 6 days. NF-KB and pNF-KB in OVCAR-5 control clusters $(\mathbf{g}$ and $\mathbf{h}$ ) treated with resveratrol (i and $\mathbf{j}$ ) or acetyl-resveratrol (k and $\mathbf{I})$ for 6 days. NF-kB and pNF-kB were stained red and nuclei were stained blue

and $30 \mu \mathrm{M}$ significantly reduced pNF-kB (Fig. 7a and b) and NF-kB (Fig. $7 \mathrm{a}$ and $\mathrm{c}$ ). $\mathrm{pI} \mathrm{kB} \alpha$ and PCNA were unaffected by the presence of resveratrol or acetylresveratrol.

\section{Attenuation of cell growth and VEGF secretion by a NF-KB inhibitor}

To assess if the NF- $\mathrm{kB}$ protein is associated with cell growth, we employed Bay 11-7085, a specific NF- $\mathrm{B}$ inhibitor. SKOV3 and OVCAR5 aggregates were treated for 6 days with inhibitor at the same concentrations as resveratrol in the previous experiments. Both metabolism and growth of the SKOV3 aggregates was reduced in a dose dependent fashion by as much as 79 and 52\%, respectively (Fig. 8a and b). The metabolism and growth of OVCAR5 clusters was also adversely affected, however, the inhibitor was not as effective. Metabolism decreased by only $40 \%$ at the most and growth by $28 \%$ (Fig. $8 \mathrm{a}$ and b). The secretion of VEGF and IL- 8 by SKOV3 aggregates was also dose-dependently reduced by the NF- $\kappa \mathrm{B}$ inhibitor, $30 \mu \mathrm{M}$ of the inhibitor decreased VEGF secretion by $96 \%$ and IL- 8 by $54 \%$ when compared to the control (Fig. 8c and d). Conversely, OVCAR5 clusters secreted slightly more VEGF and IL-8 when challenged (Fig. 8c and d).

\section{Discussion}

Of all the gynaecological cancers ovarian cancer is the deadliest. It is very difficult to detect, therefore, three quarters of patients upon diagnosis already have an advanced stage of the disease. The current treatment options for this cancer usually become ineffective after a while and overall survival rates are not good. Finding alternative treatments and targets related to chemoresistance is of the utmost importance.

Advanced ovarian cancer disseminates via cells in ascitic fluid, in which the cells survive by aggregating together [5]. These aggregates then settle at a secondary location and grow into tumours. The morphology of metastasising ovarian cancer cells has been implicated in the development of chemoresistance [6]. Targeting aggregates that are formed by these cells, therefore, could be very useful in the treatment of ovarian cancer. In this study, we grew 3D aggregates of the SKOV-3 and OVCAR-5 cell lines and demonstrate that resveratrol and acetyl-resveratrol are capable of restricting the growth and metabolism of the SKOV-3 aggregates in a time- and dose-dependent manner. We used a $10 \mu \mathrm{M}$ dose as this concentration can be found in food products and is pharmacologically relevant [29]. Previously we have tested 5,10, 50 and $100 \mu \mathrm{M}$ resveratrol and acetyl resveratrol [32] and found that 50 and $100 \mu \mathrm{M}$ of both compounds was able to reduce cell growth and increase cleaved PARP protein. Therefore, we chose to investigate $20 \mu \mathrm{M}$ and $30 \mu \mathrm{M}$ as they are in between the pharmacologically relevant dose and the previously established effective dose. OVCAR-5 cell clusters showed limited responses to resveratrol and its derivative. 
a

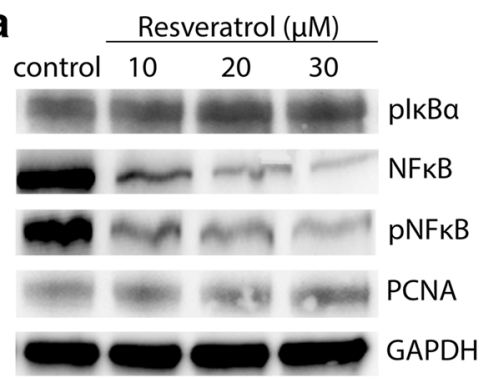

b

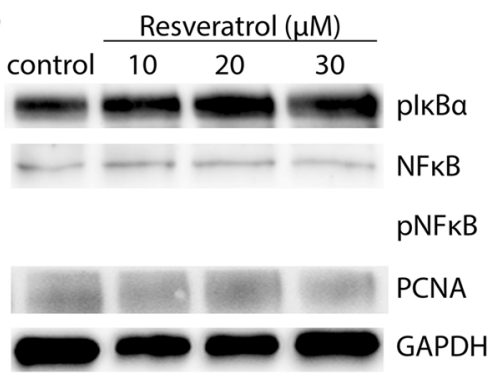

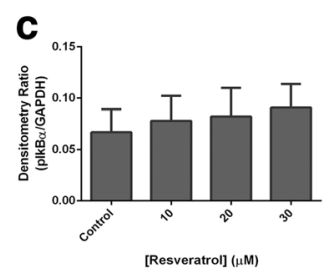
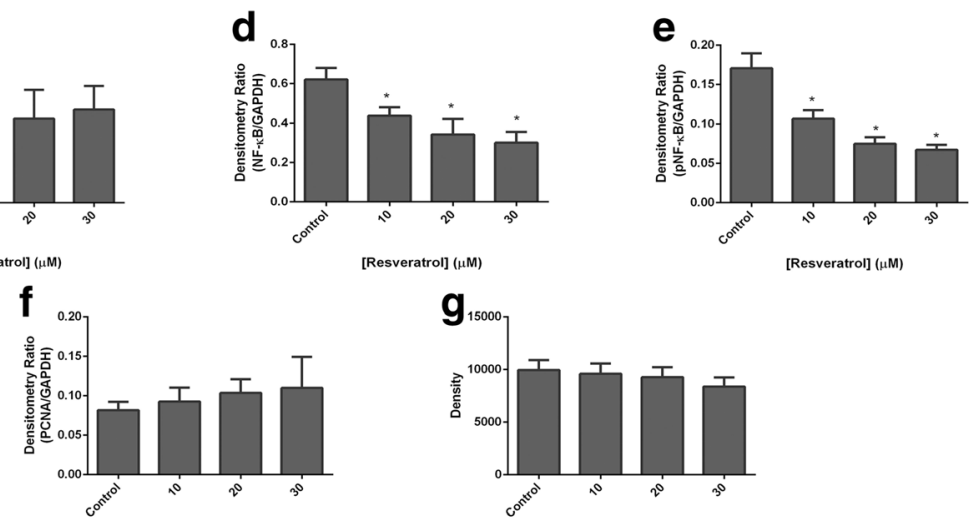

$\mathbf{g}_{\text {soon }}$
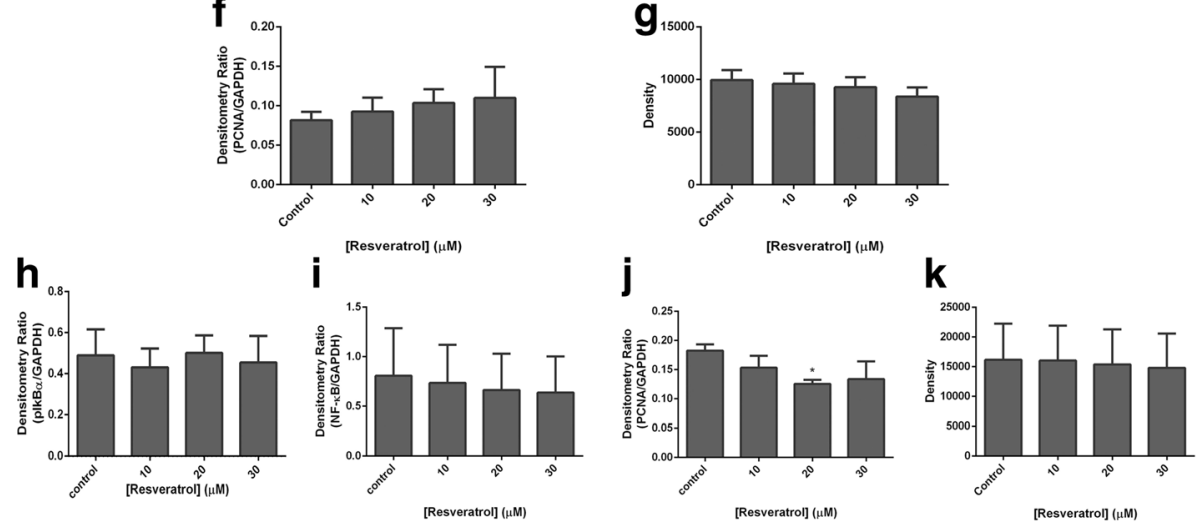

Fig. 6 Western blot analysis of SKOV-3 aggregates (a) and OVCAR-5 clusters (b) treated with resveratrol for 6 days. Densitometry ratios relative to GAPDH of pNF-KB, NF-kB, plkBa and PCNA of SKOV-3 aggregates (c, $\mathbf{d}, \mathbf{e}$ and $\mathbf{f})$ and of OVCAR-5 clusters $(\mathbf{g}, \mathbf{h}, \mathbf{i}$ and $\mathbf{j})$. * indicates statistical significance $p<0.05$ compared to the control. $n=4$ independent experiments in triplicate. GAPDH expression is a house keeping protein $(\mathbf{k})$

Resveratrol has been shown to be capable of reducing cancer growth in previous studies [38-41]. However, these studies use very high doses of the compound, for example Dann et al [38] used $100 \mu \mathrm{M}$ and Ji et al [39] used up to $200 \mu \mathrm{M}$. Furthermore, we have measured the effect of repeat doses over a long time period as we hypothesised that because of the morphology of the ovarian cancer aggregates a much longer exposure time would be required to observe any changes. In contrast, the majority of the studies done to date have been in monolayer cultures using high doses of resveratrol and measuring its effects over short time periods [42-44]. The concentrations of resveratrol and its derivative in our study did not decrease the total expression of PCNA. It may be possible that due to the cell aggregate morphology there are different metabolic cell populations within the aggregates; cells that are at the rim are fully exposed to nutrients and would divide faster than cells inside the aggregates. When these aggregates are exposed to resveratrol and acetyl-resveratrol, cell integrity at the rim may be compromised and that may allow nutrients to penetrate deeper inside the aggregate. As a consequence, this will trigger cells inside the aggregates to express PCNA [45]. Therefore, although there are less cells overall in treated aggregates, PCNA may be expressed by cells further inside the smaller aggregates compared to the large control aggregates, thus, PCNA appears to be unchanged after treatment.

The pathogenesis of ovarian cancer is dependent on various molecules present in peritoneal fluid. VEGF is a key regulator of angiogenesis, a physiological process that is very important to cancer survival, which is associated with cell proliferation [7] and migration [46]. VEGF is highly expressed by ovarian cancer and bystander cells and its concentration is associated with tumour aggression and a poor prognosis [34], as such it is implicated in ovarian cancer pathology. The current study measured the expression of VEGF after treatments with resveratrol and acetyl-resveratrol and found that the VEGF production from SKOV-3 cell aggregates was attenuated 

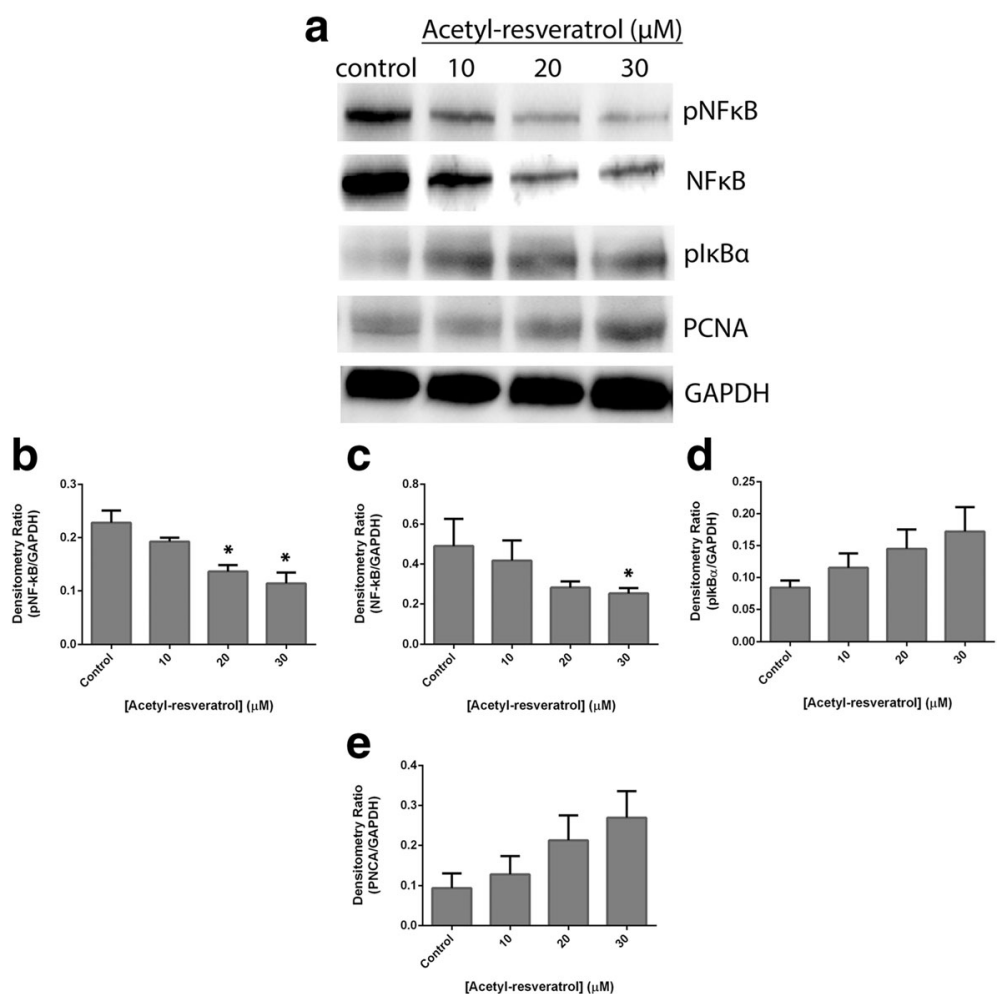

Fig. 7 Western blot analysis of SKOV-3 aggregates (a) treated with acetyl-resveratrol for 6 days. Densitometry ratios relative to GAPDH of pNF-KB (b), NF-KB (c), plkBa (d) and PCNA (e). * indicates statistical significance $p<0.05$ compared to the control. $n=4$ independent experiments in triplicate
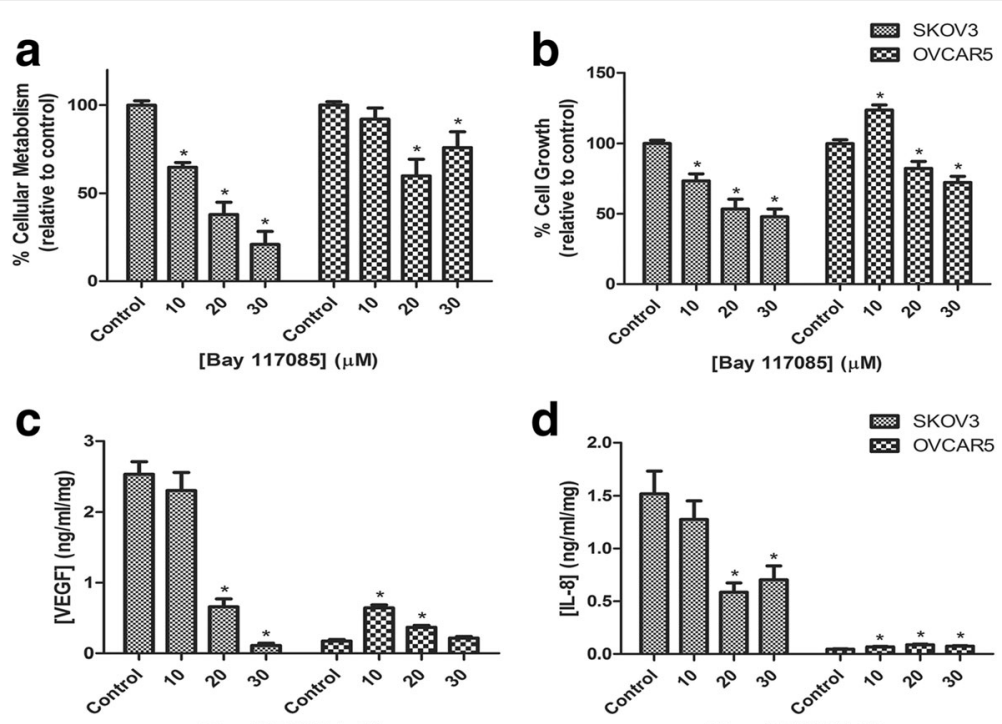

Fig. 8 Treatment of SKOV-3 aggregates and OVCAR-5 clusters with Bay 11-7085. Cellular metabolism (a) and cell growth (b) are relative to control after 6 days treatment. The secretion of VEGF (c) and IL-8 (d) measured after 6 days of treatment. ${ }^{*}$ indicates statistical significance $p<0.05$ compared to the control. $n=4$ independent experiments in triplicate 
by both compounds. The decrease in VEGF secretion correlates with the time- and dose-dependent growth restriction of SKOV-3, this result is in accordance with previous monolayer studies [47-49]. The level of VEGF secretion by OVCAR- 5 was, however, very low (on average 8-fold less than SKOV-3) and unaffected by the treatments. This difference between cell lines, although not exclusively studied before, was not totally unexpected. The cell lines were chosen as they have different receptors for adhesion [50] and have different morphology when grown as a monolayer or as 3D cell aggregates or clusters. SKOV-3 cells form large dense aggregates, whereas OVCAR-5 cells form small clusters. The distinct morphology of the cell lines in the 3D model may contribute to the activation of signalling molecules that associate with the transcriptional profile of VEGF.

Unexpectedly the secretion response of IL-8 is the reverse of VEGF. IL-8 is a cytokine that under normal conditions is involved in the inflammatory process, where it attracts and activates neutrophils at the site of infection [35], and is also a potent promoter of angiogenesis [51]. Both of these processes are keys to cancer cell survival and metastasis. Furthermore, IL- 8 has been shown to have these effects in ovarian cancer $[36,52]$. Huang et al. [53] indicated that VEGF and IL-8 secretion are closely correlated and even potentially controlled by the same intracellular signalling pathway. Additional studies even suggest that IL- 8 controls the expression of VEGF [54]. However, the effect we elicited on IL-8 with resveratrol and acetyl-resveratrol is contrary to these suppositions. The increased secretion of IL- 8 in response to resveratrol has been observed before in normal human keratinocytes [55]. Potapovich et al. [55] first stimulated the cells with TNF $\alpha$ and then challenged them with $50 \mu \mathrm{M}$ resveratrol and found that IL-8 secretion was upregulated. Considering all this evidence, we propose that resveratrol is suppressing one signalling pathway that controls VEGF expression whilst possibly up-regulating one that controls IL-8 expression. It is possible that the production of IL-8 in our study conditions may reflect a compensatory mechanism that the cancer cells are using to overcome the lack of VEGF.

In an effort to elucidate the molecules or mechanism targeted by resveratrol and acetyl-resveratrol, we measured the expression of proteins associated with the NF- $\mathrm{KB}$ signalling pathway. NF- $\mathrm{KB}$ is a family of 5 transcription factors in mammalian cells, RelA (p65), RelB, c-Rel, p50/p105 (NF-kB1) and p52/p100 (NF-kB2), which are able to form homo- and hetero-dimers [15]. The NF- $\mathrm{KB}$ cascade involves this family as well as the upstream protein I $\mathrm{K} B \alpha$ and toll-like receptors. Phosphorylation of NF- $\mathrm{kB}$ is implicated to be important to the transcription of IL-8 [56]. The NF-kB family and signalling pathway promotes proliferation via regulation of genes such as cyclin D1, D3, has been linked to gastric [18], prostate [20] and breast malignancies [19] and has been studied extensively in lymphomas [57-59]. Our data shows that the NF- $\mathrm{KB}$ protein is attenuated by resveratrol and acetyl-resveratrol, and the expression of NF- $\mathrm{KB}$ observed in the nucleus in the SKOV-3 cell aggregates is markedly reduced. The phosphorylated form of the upstream protein $\mathrm{I} \kappa \mathrm{B} \alpha$ was unaffected. We have also shown via NF- $\mathrm{kB}$ inhibition that the NF- $\mathrm{kB}$ protein is involved in the cell growth and secretion of VEGF of the cell lines. The inhibition of NF-kB was twice as effective as resveratrol in reducing cell metabolism, growth and VEGF secretion of the SKOV-3 aggregates suggesting that resveratrol may not be a single action compound, this is further supported by the opposing trends of IL- 8 secretion between resveratrol and the NF$\kappa \mathrm{B}$ inhibitor. In OVCAR- 5 cell clusters, NF- $\mathrm{BB}$ expression is very low and rarely visualized in the nucleus, whilst pNF- $\mathrm{kB}$ was below detectable levels, the cell growth was reduced by NF- $k B$ inhibition, however, to a much lesser extent than the SKOV-3 aggregates. Taken together, these results may suggest that resveratrol and acetyl-resveratrol may attenuate the secretion of VEGF via the reduction of NF- $\mathrm{KB}$ protein level. It is possible that resveratrol and acetyl-resveratrol may be affecting the NF- $\mathrm{KB}$ protein at the transcriptional level. The present study is limited given the lack of growth effects of resveratrol and its derivative in normal ovarian epithelial cells.

\section{Conclusion}

Taken together, our results suggest that resveratrol and acetyl-resveratrol may exhibit anti-ovarian cancer properties through the inhibition of NF- $\mathrm{kB}$. The polyphenols were able to reduce the growth of $3 \mathrm{D}$ ovarian cancer cells in a cell line-, concentration- and time-dependant manner. This growth restriction correlated with reduction and reduced nuclear localisation of the NF- $\mathrm{kB}$ protein. The reduction of NF- $k B$ in turn correlated with the attenuation of VEGF secretion. Further studies of the anti-ovarian cancer growth activity of resveratrol and acetyl-resveratrol are warranted especially using in vivo animal models before clinical trials.

\footnotetext{
Acknowledgements

We thank Health Research Council (HRC), New Zealand for Alex Tino's scholarship.

The authors declare that the work described has not been published previously.
}

\section{Funding}

This study was partly funded by Ovarian Cancer Research Foundation (OCRF), Melbourne, Australia. 


\section{Availability of data and materials}

The data supporting the conclusion of this article is included within the article.

\section{Authors' contributions}

AT did experiments and prepared a manuscript. KC assisted with experiments and prepared a manuscript. PS assisted with manuscript preparation. AG assisted with experimental design and prepared manuscript. All authors read and approved the final manuscript.

\section{Competing interests}

The authors declare that they have no competing interests.

\section{Consent for publication}

Not applicable.

\section{Ethics approval and consent to participate}

Not applicable.

\section{Author details}

'Department of Obstetrics and Gynaecology, University of Otago, Christchurch, 2 Riccarton Avenue, Christchurch 8011, New Zealand. 2Obstetrics and Gynaecology Department Christchurch Women's Hospital, Private Bag 4711, Christchurch 8140, New Zealand. ${ }^{3}$ School of Biological Sciences, University of Canterbury, Private Bag 4800, Christchurch 8140, New Zealand.

\section{Received: 25 May 2016 Accepted: 26 November 2016}

Published online: 01 December 2016

\section{References}

1. Ferlay J, Soerjomataram I, Ervik M, Dikshit R, Eser S, Mathers C, et al.: GLOBOCAN 2012 v1. 0, Cancer incidence and mortality worldwide: IARC CancerBase No. 11. 2013. Available from: globocan iarc fr. 2014.

2. Bast RC, Hennessy B, Mills GB. The biology of ovarian cancer: new opportunities for translation. Nat Rev Cancer. 2009;9(6):415-28.

3. Bhoola S, Hoskins WJ. Diagnosis and management of epithelial ovarian cancer. Obstet Gynecol. 2006;107(6):1399-410.

4. Dembo AJ, Dave M, Stenwig AE, Berle EJ, Bush RS, Kjorstad K. Prognostic factors in patients with stage I epithelial ovarian cancer. Obstet Gynecol. 1990;75(2):263-73.

5. Ahmed N, Thompson EW, Quinn MA. Epithelial-mesenchymal interconversions in normal ovarian surface epithelium and ovarian carcinomas: an exception to the norm. J Cell Physiol. 2007;213(3):581-8.

6. Loessner D, Stok KS, Lutolf MP, Hutmacher DW, Clements JA, Rizzi SC. Bioengineered 3D platform to explore cell-ECM interactions and drug resistance of epithelial ovarian cancer cells. Biomaterials. 2010;31(32): 8494-506.

7. Masood R, Cai J, Zheng T, Smith DL, Hinton DR, Gill PS. Vascular endothelial growth factor (VEGF) is an autocrine growth factor for VEGF receptorpositive human tumors. Blood J Am Soc Hematol. 2001;98(6):1904-13.

8. Senger DR, Ledbetter SR, Claffey KP, Papadopoulos-Sergiou A, Peruzzi C, Detmar M. Stimulation of endothelial cell migration by vascular permeability factor/vascular endothelial growth factor through cooperative mechanisms involving the alphavbeta3 integrin, osteopontin, and thrombin. Am J Pathol. 1996;149(1):293.

9. Nakanishi Y, Kodama J, Yoshinouchi M, Tokumo K, Kamimura S, Okuda H, et al. The expression of vascular endothelial growth factor and transforming growth factor-[beta] associates with angiogenesis in epithelial ovarian cancer. Int J Gynecol Pathol. 1997;16(3):256-62.

10. Zebrowski BK, Liu W, Ramirez K, Akagi Y, Mills GB, Ellis LM. Markedly elevated levels of vascular endothelial growth factor in malignant ascites. Ann Surg Oncol. 1999:6(4):373-8.

11. Browne A, Sriraksa R, Guney T, Rama N, Van Noorden S, Curry E, et al. Differential expression of IL-8 and IL-8 receptors in benign, borderline and malignant ovarian epithelial tumours. Cytokine. 2013;64(1):413-21.

12. Kassim SK, El-Salahy EM, Fayed ST, Helal SA, Helal T, Azzam EE-d. Vascular endothelial growth factor and interleukin-8 are associated with poor prognosis in epithelial ovarian cancer patients. Clin Biochem. 2004;37(5): 363-9.
13. Schutyser E, Struyf S, Proost P, Opdenakker G, Laureys G, Verhasselt B, et al. Identification of biologically active chemokine isoforms from ascitic fluid and elevated levels of CCL18/pulmonary and activation-regulated chemokine in ovarian carcinoma. J Biol Chem. 2002;277(27):24584-93.

14. Rhode J, Fogoros S, Zick S, Wahl H, Griffith KA, Huang J, et al. Ginger inhibits cell growth and modulates angiogenic factors in ovarian cancer cells. BMC Complement Altern Med. 2007;7(1):1

15. Dolcet X, Llobet D, Pallares J, Matias-Guiu X. NF-kB in development and progression of human cancer. Virchows Arch. 2005;446(5):475-82.

16. De Simone V, Franze E, Ronchetti G, Colantoni A, Fantini M, Di Fusco D, et al. Th17-type cytokines, IL-6 and TNF-a synergistically activate STAT3 and NF-kB to promote colorectal cancer cell growth. Oncogene. 2015;34(27): 3493-503.

17. Sovak MA, Bellas RE, Kim DW, Zanieski GJ, Rogers AE, Traish AM, et al. Aberrant nuclear factor-kappaB/Rel expression and the pathogenesis of breast cancer. J Clin Investig. 1997;100(12):2952.

18. Xia J, Chen L, Jian W, Wang K-B, Yang Y, He W, et al. MicroRNA-362 induces cell proliferation and apoptosis resistance in gastric cancer by activation of NF-kB signaling. J Transl Med. 2014;12(1):33.

19. Gonzalez-Perez RR, Xu Y, Guo S, Watters A, Zhou W, Leibovich SJ. Leptin upregulates VEGF in breast cancer via canonic and non-canonical signalling pathways and NFKB/HIF-1a activation. Cell Signal. 2010;22(9):1350-62.

20. Hirsch J, Johnson CL, Nelius T, Kennedy R, de Riese W, Filleur S. PEDF inhibits IL8 production in prostate cancer cells through PEDF receptor/phospholipase A2 and regulation of NFKB and PPARY. Cytokine. 2011;55(2):202-10.

21. Lanzilli G, Cottarelli A, Nicotera G, Guida S, Ravagnan G, Fuggetta MP. Anti-inflammatory effect of resveratrol and polydatin by in vitro $\mathrm{IL}-17$ modulation. Inflammation. 2012;35(1):240-8.

22. Magyar K, Halmosi R, Palfi A, Feher G, Czopf L, Fulop A, et al. Cardioprotection by resveratrol: A human clinical trial in patients with stable coronary artery disease. Clin Hemorheol Microcirc. 2012;50(3):179-87.

23. Shukla Y, Singh R. Resveratrol and cellular mechanisms of cancer prevention. Ann N Y Acad Sci. 2011;1215(1):1-8.

24. Benitez DA, Hermoso MA, Pozo-Guisado E, Fernández-Salquero PM, Castellón EA. Regulation of cell survival by resveratrol involves inhibition of NFKB regulated gene expression in prostate cancer cells. Prostate. 2009; 69(10):1045-54.

25. Karthikeyan S, Hoti SL, Prasad NR. Resveratrol loaded gelatin nanoparticles synergistically inhibits cell cycle progression and constitutive NF-kappaB activation, and induces apoptosis in non-small cell lung cancer cells. Biomed Pharmacother. 2015;70:274-82.

26. Park SY, Jeong KJ, Lee J, Yoon DS, Choi WS, Kim YK, et al. Hypoxia enhances LPA-induced HIF-1alpha and VEGF expression: their inhibition by resveratrol. Cancer Lett. 2007;258(1):63-9.

27. Cullberg KB, Olholm J, Paulsen SK, Foldager CB, Lind M, Richelsen B, et al. Resveratrol has inhibitory effects on the hypoxia-induced inflammation and angiogenesis in human adipose tissue in vitro. Eur J Pharm Sci. 2013:49(2): 251-7.

28. Walle T. Bioavailability of resveratrol. Ann N Y Acad Sci. 2011;1215(1):9-15.

29. Baur JA, Sinclair DA. Therapeutic potential of resveratrol: the in vivo evidence. Nat Rev Drug Discov. 2006;5(6):493-506.

30. Colin D, Gimazane A, Lizard G, Izard JC, Solary E, Latruffe N, et al. Effects of resveratrol analogs on cell cycle progression, cell cycle associated proteins and 5 fluoro-uracil sensitivity in human derived colon cancer cells. Int J Cancer. 2009;124(12):2780-8

31. Liang L, Liu X, Wang Q, Cheng S, Zhang S, Zhang M. Pharmacokinetics, tissue distribution and excretion study of resveratrol and its prodrug 3,5,4'tri-O-acetylresveratrol in rats. Phytomedicine. 2013;20(6):558-63.

32. Hogg SJ, Chitcholtan K, Hassan W, Sykes PH, Garrill A. Resveratrol, acetylresveratrol and polydatin exhibit anti-growth activity against 3D cell aggregates of the SKOV-3 and OVCAR- 8 ovarian cancer cell lines. Obstet Gynecol Int. 2015;2015:14.

33. Fidler IJ, Ellis LM. The implications of angiogenesis for the biology and therapy of cancer metastasis. Cell. 1994;79(2):185-8.

34. Cheng D, Liang B, Li Y. Serum vascular endothelial growth factor (VEGF-C) as a diagnostic and prognostic marker in patients with ovarian cancer. PLoS One. 2013;8(2):e55309.

35. Matsukawa A, Yoshimura T, Maeda T, Ohkawara S, Takagi K, Yoshinaga M. Neutrophil accumulation and activation by homologous IL-8 in rabbits. IL-8 induces destruction of cartilage and production of $\mathrm{IL}-1$ and $\mathrm{IL}-1$ receptor antagonist in vivo. J Immuno. 1995;154(10):5418-25. 
36. Shahzad MM, Arevalo JM, Armaiz-Pena GN, Lu C, Stone RL, Moreno-Smith $M$, et al. Stress effects on FosB-and interleukin-8 (IL8)-driven ovarian cancer growth and metastasis. J Biol Chem. 2010;285(46):35462-70.

37. Lane D, Matte I, Rancourt C, Piche A. Prognostic significance of IL-6 and IL-8 ascites levels in ovarian cancer patients. BMC Cancer. 2011;11(210): 1471-2407.

38. Dann JM, Sykes PH, Mason DR, Evans JJ. Regulation of vascular endothelial growth factor in endometrial tumour cells by resveratrol and EGCG. Gynecol Oncol. 2009;113(3):374-8.

39. Ji Q, Liu X, Fu X, Zhang L, Sui H, Zhou L, et al. Resveratrol inhibits invasion and metastasis of colorectal cancer cells via MALAT1 mediated Wnt/ $\beta$ catenin signal pathway. PLoS One. 2013;8(11):e78700.

40. Joe AK, Liu H, Suzui M, Vural ME, Xiao D, Weinstein IB. Resveratrol induces growth inhibition, S-phase arrest, apoptosis, and changes in biomarker expression in several human cancer cell lines. Clin Cancer Res. 2002;8(3): 893-903.

41. Selvaraj S, Sun Y, Sukumaran P, Singh BB. Resveratrol activates autophagic cell death in prostate cancer cells via downregulation of STIM1 and the mTOR pathway. Mol Carcinog. 2015;55(5):818-31.

42. Gwak H, Kim S, Dhanasekaran DN, Song YS. Resveratrol triggers ER stressmediated apoptosis by disrupting $\mathrm{N}$-linked glycosylation of proteins in ovarian cancer cells. Cancer Lett. 2016;371(2):347-53.

43. Vergara D, Simeone P, Toraldo D, Del Boccio P, Vergaro V, Leporatti S, et al. Resveratrol downregulates Akt/GSK and ERK signalling pathways in OVCAR3 ovarian cancer cells. Mol Biosyst. 2012;8(4):1078-87.

44. Zhong L-X, Li H, Wu M-L, Liu X-Y, Zhong M-J, Chen X-Y, et al. Inhibition of STAT3 signaling as critical molecular event in resveratrol-suppressed ovarian cancer cells. J Ovarian Res. 2015;8(1):1.

45. Chitcholtan K, Sykes P, Evans J. The resistance of intracellular mediators to doxorubicin and cisplatin are distinct in 3D and 2D endometrial cancer. J Transl Med. 2012;10:38.

46. De Luca A, Lamura L, Gallo M, Maffia V, Normanno N. Mesenchymal stem cell-derived interleukin-6 and vascular endothelial growth factor promote breast cancer cell migration. J Cell Biochem. 2012;113(11):3363-70.

47. Bai Y, Mao QQ, Qin J, Zheng XY, Wang YB, Yang K, et al. Resveratrol induces apoptosis and cell cycle arrest of human T24 bladder cancer cells in vitro and inhibits tumor growth in vivo. Cancer Sci. 2010;101(2):488-93.

48. Foy KC, Liu Z, Phillips G, Miller M, Kaumaya PT. Combination treatment with HER-2 and VEGF peptide mimics induces potent anti-tumor and antiangiogenic responses in vitro and in vivo. J Biol Chem. 2011;286(15): 13626-37.

49. Trapp V, Parmakhtiar B, Papazian V, Willmott L, Fruehauf JP. Anti-angiogenic effects of resveratrol mediated by decreased VEGF and increased TSP1 expression in melanoma-endothelial cell co-culture. Angiogenesis. 2010; 13(4):305-15.

50. Lessan K, Aguiar DJ, Oegema T, Siebenson L, Skubitz PN. CD44 and B1 Integrin mediate ovarian carcinoma cell adhesion to peritoneal mesothelial cells. Am J Pathol. 1999;154(5):1525-37.

51. Koch AE, Polverini PJ, Kunkel SL, Harlow LA, DiPietro LA, Elner VM, et al. Interleukin-8 as a macrophage-derived mediator of angiogenesis. Science. 1992;258:1798-801.

52. Wang Y, Yang J, Gao Y, Du Y, Bao L, Niu W, et al. Regulatory effect of E2, IL-6 and IL-8 on the growth of epithelial ovarian cancer cells. Cell Mol Immunol. 2005;2(5):365-72.

53. Huang S, Robinson JB, DeGuzman A, Bucana CD, Fidler IJ. Blockade of nuclear factor-KB signaling inhibits angiogenesis and tumorigenicity of human ovarian cancer cells by suppressing expression of vascular endothelial growth factor and interleukin 8. Cancer Res. 2000;60(19):5334-9.

54. Martin D, Galisteo R, Gutkind JS. CXCL8/IL8 stimulates vascular endothelial growth factor (VEGF) expression and the autocrine activation of VEGFR2 in endothelial cells by activating NFKB through the CBM (Carma3/Bcl10/Malt1) complex. J Biol Chem. 2009;284(10):6038-42.

55. Potapovich Al, Lulli D, Fidanza P, Kostyuk VA, De Luca C, Pastore $S$, et al. Plant polyphenols differentially modulate inflammatory responses of human keratinocytes by interfering with activation of transcription factors NFkappaB and AhR and EGFR-ERK pathway. Toxicol Appl Pharmacol. 2011; 255(2):138-49

56. Nowak DE, Tian B, Jamaluddin M, Boldogh I, Vergara LA, Choudhary S, et al. RelA Ser276 phosphorylation is required for activation of a subset of NF-KBdependent genes by recruiting cyclin-dependent kinase 9/cyclin T1 complexes. Mol Cell Biol. 2008;28(11):3623-38.
57. Hathcock KS, Padilla-Nash HM, Camps J, Shin D-M, Triner D, Shaffer AL, et al. ATM deficiency in absence of T cells promotes development of NF-kBdependent murine $B$ cell lymphomas that resemble human $A B C D L B C L$. Blood. 2015:blood-2015-06-654749.

58. Montesinos-Rongen M, Schmitz R, Brunn A, Gesk S, Richter J, Hong K, et al. Mutations of CARD11 but not TNFAIP3 may activate the NF-KB pathway in primary CNS lymphoma. Acta Neuropathol. 2010;120(4):529-35.

59. Rayet B, Gelinas C. Aberrant rel/nfkb genes and activity in human cancer. Oncogene. 1999;18(49):6938-47.

\section{Submit your next manuscript to BioMed Central and we will help you at every step:}

- We accept pre-submission inquiries

- Our selector tool helps you to find the most relevant journal

- We provide round the clock customer support

- Convenient online submission

- Thorough peer review

- Inclusion in PubMed and all major indexing services

- Maximum visibility for your research

Submit your manuscript at www.biomedcentral.com/submit
Biomed Central 